\title{
Combined Treatment Strategies for Unconjugated Hyperbilirubinemia in Gunn Rats
}

\author{
FRANS J. C. CUPERUS, ARJAN A. IEMHOFF, AND HENKJAN J. VERKADE \\ Department of Pediatrics, Beatrix Children's Hospital-University Medical Center Groningen, University of Groningen, 9700 RB \\ Groningen, The Netherlands
}

\begin{abstract}
We recently demonstrated that acceleration of the gastrointestinal transit by polyethylene glycol (PEG) treats unconjugated hyperbilirubinemia in jaundiced Gunn rats. It is unclear whether acceleration of gastrointestinal transit also (partly) underlies the therapeutic effects of established hypobilirubinemic treatments or whether PEG cotreatment might enhance these effects. We treated Gunn rats with phototherapy $\left(17 \mu \mathrm{W} / \mathrm{cm}^{2} / \mathrm{nm}\right)$, orlistat $(200 \mathrm{mg} / \mathrm{kg}$ chow), ursodeoxycholate $(5 \mathrm{~g} / \mathrm{kg}$ chow), or calcium phosphate $(\mathrm{CaP})$ (20 g/kg chow) either as single treatment or in combination with PEG. Three weeks of phototherapy, orlistat, ursodeoxycholic acid, or $\mathrm{CaP}$ treatment decreased plasma unconjugated bilirubin (UCB) levels by $47,27,28$, and $45 \%$, respectively (each $p<0.001$ ), without a significant impact on gastrointestinal transit time. PEG cotreatment accelerated the gastrointestinal transit in all treatment groups, which resulted in an additive hypobilirubinemic effect of $-20 \%$ and $-26 \%$ (final plasma UCB -67 and $-53 \%$, respectively) in phototherapyand orlistat-treated animals. PEG cotreatment did not enhance the hypobilirubinemic effect of ursodeoxycholic acid or CaP. We conclude that phototherapy, orlistat, ursodoxycholic acid, and $\mathrm{CaP}$ do not exert their hypobilirubinemic effect via acceleration of the gastrointestinal transit. PEG cotreatment enhanced the hypobilirubinemic effects of phototherapy and of orlistat treatment. Current results support a clinical trial to evaluate PEG cotreatment during phototherapy. (Pediatr Res 70: 560-565, 2011)
\end{abstract}

$\mathrm{N}^{\circ}$ eonatal hemolytic jaundice and Crigler-Najjar disease are characterized by severe unconjugated hyperbilirubinemia. In Crigler-Najjar patients, a genetically absent (type I) or decreased (type II) ability to conjugate bilirubin within the liver results in lifelong jaundice $(1,2)$. Unconjugated bilirubin (UCB) is neurotoxic, and severe unconjugated hyperbilirubinemia is associated with brain damage (3). This damage occurs because nonprotein-bound plasma bilirubin $\left(\mathrm{UCB}_{\text {free }}\right)$ can diffuse across the blood-brain barrier (4-9). To decrease plasma UCB levels, Crigler-Najjar disease patients rely on lifelong phototherapy, the routine treatment for unconjugated hyperbilirubinemia. Phototherapy, however, becomes less effective with age and eventually fails to prevent bilirubin-induced brain damage in up to $25 \%$ of Crigler-Najjar patients $(10,11)$. This prompted us to develop alternative and

Received January 26, 2011; accepted June 27, 2011

Correspondence: Henkjan J. Verkade, M.D., Ph.D., Beatrix Children's HospitalUniversity Medical Center Groningen, Pediatric Gastroenterology, Room Y4.139, P.O. Box 30.001, 9700 RB Groningen, The Netherlands; e-mail: h.j.verkade@umcg.nl

Supported by an unrestricted grant from Hutchinson Whampoa Ltd. and the University of Groningen [to F.J.C.C.].

The authors report no conflicts of interest. adjunct, treatment strategies for severe unconjugated hyperbilirubinemia.

Severe unconjugated hyperbilirubinemia allows direct transmucosal diffusion of $\mathrm{UCB}_{\text {free }}$ from the blood into the intestine (12-14). The efficacy of this pathway is decreased, however, by the intestines' ability to reabsorb $\mathrm{UCB}_{\text {free }}$ from its lumen $(12,15)$. We recently hypothesized that acceleration of the gastrointestinal transit might interfere with this ability and thus enhance the efficacy of transmucosal bilirubin disposal. Indeed, the laxative polyethylene glycol (PEG) proved an effective treatment for unconjugated hyperbilirubinemia in Gunn rats, the animal model for Crigler-Najjars disease (16). Importantly, our experiments also revealed a strong linear relation between the gastrointestinal transit time and plasma UCB levels in these animals (16).

Our results raised the question whether other treatments also (partly) rely on acceleration of the gastrointestinal transit for their hypobilirubinemic effects. Interestingly, previous findings have suggested that phototherapy and oral treatments that enhance transmucosal UCB diffusion [e.g. orlistat $(17,18)$, bile salts (13), or amorphous calcium phosphate (CaP) (19)] might indeed influence transit time (20-25). We presently show that neither phototherapy nor oral treatment with orlistat, ursodeoxycholic acid (UDCA), or CaP affects the gastrointestinal transit time in Gunn rats. We also show that addition of PEG to either phototherapy or orlistat treatment enhances their hypobilirubinemic effect.

\section{ANIMALS, MATERIALS, AND METHODS}

Animals. Homozygous male Gunn rats (RHA/jj; 244-375 g; $n=60$ ) were obtained from our breeding colony at the University Medical Center Groningen (UMCG, The Netherlands). Animals, housed individually in an environmentally controlled facility with a diurnal (12/12 h) light cycle, were fed ad libitum and had free access to water. The Ethics Committee for Animal Experiments of the UMCG approved the experimental protocols for this study.

Materials. Diets. Hope Farms BV (Woerden, The Netherlands) produced all diets. The semisynthetic control diet (code 4063.02) contained 13\% energy fat (17). Supplemented diets were identical to the control diet, except for the
Abbreviations: ALT, alanine aminotransferase; AST, aspartate aminotransferase; CaP, calcium phosphate; Creat, creatinine; PEG, polyethylene glycol; UCB, unconjugated bilirubin; UCBfree, free unconjugated bilirubin; UDCA, ursodeoxycholic acid; Ur, urea 
supplementation of orlistat ( $200 \mathrm{mg} / \mathrm{kg}$ chow), UDCA ( $5 \mathrm{~g} / \mathrm{kg}$ chow), or CaP $(20 \mathrm{~g} / \mathrm{kg}$ chow). Gunn rats were fed the semisynthetic purified control diet (4063.02) during a 6-wk run-in period before the experiments (13).

Chemicals. PEG 4000 (Colofort) was obtained from Ipsen Farmaceutica B.V. (Hoofddorp, The Netherlands). Colofort contained per sachet (74 g): $64 \mathrm{~g}$ PEG, $5.7 \mathrm{~g}$ sodium sulfate (anhydric), $1.68 \mathrm{~g}$ sodium bicarbonate, $1.46 \mathrm{~g}$ sodium chloride, and $0.75 \mathrm{~g}$ potassium chloride. We dissolved one sachet of PEG 4000 (Colofort) in $900 \mathrm{~mL}$ water to obtain the PEG solution we used in our experiments (drinking water solution and gavage solution). Orlista (Xenical) was obtained from Roche Nederland B.V. (Woerden, The Netherlands). UDCA was a generous gift from Dr. Falk Pharma GmbH (Freiburg, Germany). Carmine red dye was obtained from Macro-imPulse Saveur Ltd. (Stadtoldendorf, Germany).

Phototherapy lamps. Phototherapy devices were designed according the prototype by Ostrow (26). Two phototherapy lamps (Philips TL-20 W/03 T) were suspended in a reflective framework $20 \mathrm{~cm}$ above the bottom of the cage. The light intensity of phototherapy was measured by a Dale 40 phototherapy radiometer (Dale Technologies, Carson City, NV) at $20 \mathrm{~cm}$ distance from the light source and was set to $17 \mu \mathrm{W} / \mathrm{cm}^{2} / \mathrm{nm}$. Gunn rats, shaven on their backs and flanks every $7 \mathrm{~d}$, received continuous phototherapy (27).

Methods. Long-term experiment. Male Gunn rats were randomized $(n=$ 5-6 per group) to receive no treatment (controls) or treatment with phototherapy $\left(17 \mu \mathrm{W} / \mathrm{cm}^{2} / \mathrm{nm}\right)$, orlistat ( $200 \mathrm{mg} / \mathrm{kg}$ chow), UDCA $(5 \mathrm{~g} / \mathrm{kg}$ chow), or $\mathrm{CaP}(20 \mathrm{~g} / \mathrm{kg}$ chow). Body weight was determined weekly during the experiments. After a 3-wk treatment period, which ensured the presence of steady-state conditions (13,16-18), we determined the gastrointestinal transit time in untreated (controls) and treated Gunn rats by measuring the interval between intragastrical administration of carmine red and its appearance in the feces (13). Heparinized samples of tail vein blood were obtained under isoflurane anesthesia before (baseline) and $3 \mathrm{wk}$ after randomization to determine steady-state plasma bilirubin concentrations. After $3 \mathrm{wk}$, these treatments were combined with PEG, both via drinking water and via intragastrical gavage $(2.5 \mathrm{~mL}$, every $12 \mathrm{~h})$. The gastrointestinal transit time was determined again $6 \mathrm{wk}$ after randomization $(3 \mathrm{wk}$ after the addition of PEG). A final blood sample was then obtained, as described above, for the determination of bilirubin, urea (Ur), creatinine (Creat), aspartate aminotransferase (AST), and alanine aminotransferase (ALT).

Short-term experiment. Male Gunn rats were randomized $(n=6-7$ per group) to receive no treatment (controls), phototherapy $\left(17 \mu \mathrm{W} / \mathrm{cm}^{2} / \mathrm{nm}\right)$, phototherapy $\left(17 \mu \mathrm{W} / \mathrm{cm}^{2} / \mathrm{nm}\right.$ ) combined with PEG (via drinking water and via $2.5 \mathrm{~mL}$ gavage), orlistat $(200 \mathrm{mg} / \mathrm{kg}$ chow $)$, or orlistat $(200 \mathrm{mg} / \mathrm{kg}$ chow) combined with PEG (via drinking water and via $2.5 \mathrm{~mL}$ gavage). Body weight was determined daily during the experiments. Carmine red was administered directly after the start of PEG administration to determine the gastrointestinal transit as described above. Heparinized samples of tail vein blood were obtained under isoflurane anesthesia every $12 \mathrm{~h}$ for the first $48 \mathrm{~h}$ for the determination of bilirubin, Ur, Creat, AST, and ALT. A final blood sample was obtained $14 \mathrm{~d}$ after randomization.

Plasma analysis. Blood samples were protected from light and processed immediately. Bilirubin, Ur, Creat, AST, and ALT were determined by routine spectrophotometry on a P800 unit of a modular analytics serum work area from Roche Diagnostics Ltd. (Basel, Switzerland). We previously found that the total bilirubin concentration in Gunn rat plasma, measured by spectrophotometry, equaled the total UCB concentration, measured by high-liquid performance chromatography after chloroform extraction $(17,27)$.

Statistical analysis. All data were normally distributed, displayed homogeneity of variance by calculation of Levene's statistic, and were expressed as mean $\pm \mathrm{SD}$. ANOVA with post hoc Bonferroni correction was performed for comparison between groups. $t$ test was used for comparison of paired data within groups. The level of significance was set at $p<0.05$. Analyses were performed using SPPS 16.0 for Mac (SPSS Inc., Chicago, IL).

\section{RESULTS}

\section{Long-term experiment.}

Neither phototherapy nor oral treatments affect gastrointestinal transit time. Because acceleration of gastrointestinal transit decreases plasma bilirubin concentrations in Gunn rats, we assessed whether phototherapy and known oral treatments exert their hypobilirubinemic effects, either partly or exclusively, by acceleration of the gastrointestinal transit. Figure 1 shows that $3 \mathrm{wk}$ of phototherapy, orlistat, UDCA, or $\mathrm{CaP}$ decreased plasma bilirubin concentrations by $47,27,28$,

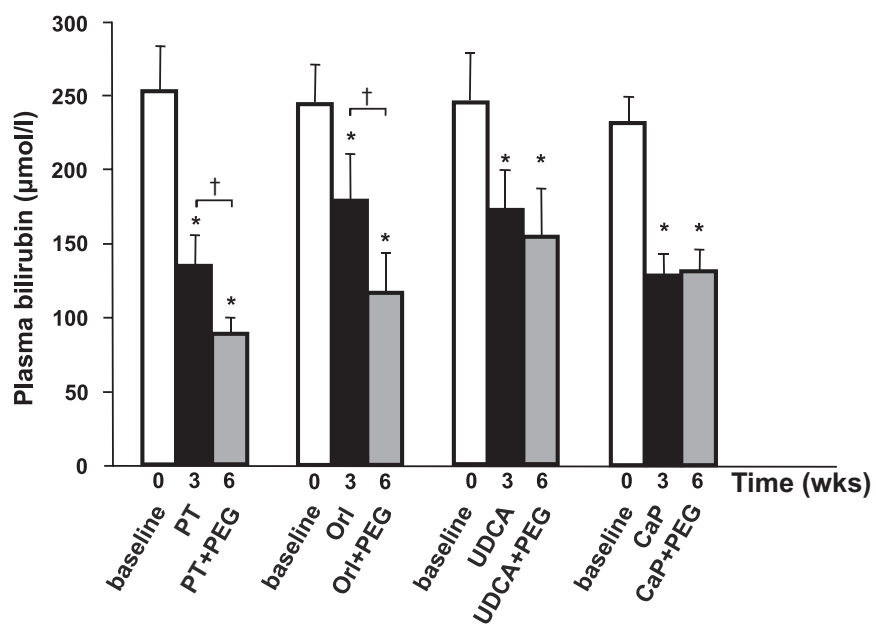

Figure 1. Treatment with continuous phototherapy $(P T)$, or oral treatment with orlistat $(\mathrm{Orl}), U D C A$, or $\mathrm{CaP}$ significantly decreased plasma bilirubin concentrations after $3 \mathrm{wk}$ and $P E G$ induced an additive therapeutic effect in phototherapy- and orlistat-treated animals. Gunn rats $(n=5-6$ per group) received either no treatment or treatment with phototherapy, orlistat, $U D C A$, or $\mathrm{CaP}$. After $3 \mathrm{wk}$, these treatments were combined with PEG administration for an additional 3 wk. ${ }^{*} p<0.001$, compared with baseline values. $\dagger p<0.01$, compared with single treatment.

and $45 \%$, respectively, compared with baseline values $(p<$ 0.001). Figure 2 shows that, after 3 wk of treatment, neither phototherapy nor oral treatments with orlistat, UDCA, or CaP significantly affected the gastrointestinal transit time, compared with controls.

Additive therapeutic effect of PEG administration on phototherapy and orlistat treatment. Because neither phototherapy nor any of the oral treatments accelerated the gastrointestinal transit, we assessed whether adjunct PEG treatment could increase their hypobilirubinemic effect. Figure 3 shows that combining phototherapy, orlistat, UDCA, and CaP with PEG administration for $3 \mathrm{wk}$ accelerated the gastrointestinal transit by $40,33,33$, and $28 \%$, respectively, compared with controls $(p<0.001$; each). Figure 1 shows that 3 wk of combined treatment of PEG with phototherapy, orlistat, UDCA, and CaP decreased plasma bilirubin concentrations by $67,53,30$, and $45 \%$, respectively, $(p<0.001)$. Combining phototherapy or orlistat treatment with PEG thus induced an additive therapeutic effect of 20 and $26 \%$, respectively, compared with single treatment $(p<0.01)$. The hypobilirubinemic effect of PEG + phototherapy is in line with our previous results, which showed a $62 \%$ decrease in plasma bilirubin levels after 2 wk of phototherapy + PEG treatment (16). Table 1 shows effect of PEG cotreatment on renal function, liver function, and growth rate in the various treatment groups. Addition of PEG to phototherapy, orlistat, UDCA, or CaP did not affect plasma levels of urea, compared with controls, which pleaded against clinically relevant dehydration during PEG cotreatment. PEG + orlistat treatment resulted in a mild increase in plasma Creat levels compared with the control group, although still within the reference range for Gunn rats (28). UDCA + PEG-treated animals showed a 5\% decrease in growth rate during the entire experiment, compared with a $2.5 \%$ increase in control animals $(p<0.01$; Table 1$)$. 


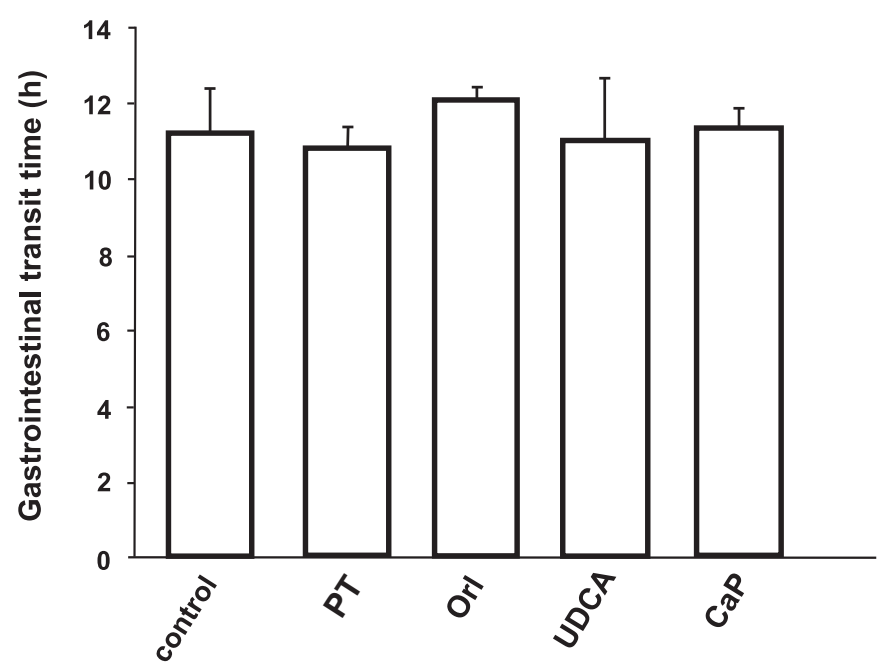

Figure 2. Three weeks of continuous phototherapy $(P T)$ or oral treatment with orlistat $(\mathrm{Orl}), U D C A$, or $\mathrm{CaP}$ did not significantly affect the gastrointestinal transit time. Gunn rats $(n=5-6$ per group) received either no treatment or treatment with phototherapy, orlistat, UDCA, or CaP. After 3 wk, we determined the gastrointestinal transit time by measuring the interval between intragastrical administration of carmine red and its appearance in the feces.

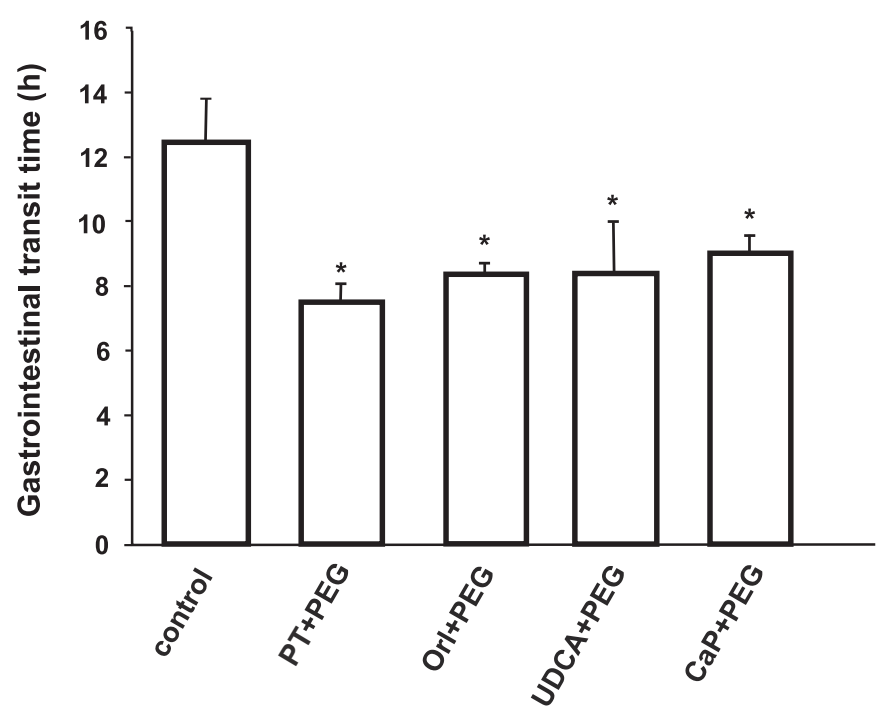

Figure 3. Combining phototherapy (PT), orlistat (Orl), UDCA, and $\mathrm{CaP}$ with $P E G$ administration significantly accelerated the gastrointestinal transit. Gunn rats ( $n=5-6$ per group) received either no treatment or treatment with phototherapy, orlistat, UDCA, or $C a P$. After $3 \mathrm{wk}$, these treatments were combined with $P E G$ administration for an additional $3 \mathrm{wk}$. After $6 \mathrm{wk}$, we determined the gastrointestinal transit time as described in Fig. 2. ${ }^{*} p<0.001$, compared with controls.

\section{Short-term experiment.}

Immediate PEG cotreatment with orlistat is effective within days. To further explore its clinical potential, we subsequently determined whether immediate PEG cotreatment could accelerate the hypobilirubinemic effect of phototherapy or orlistat during a short-term period of treatment. Figure $4 \mathrm{~A}$ shows that phototherapy alone decreased plasma bilirubin concentrations by $35 \%$ within $48 \mathrm{~h}(p<0.001)$, compared with control animals. Immediate cotreatment with PEG accelerated the gastrointestinal transit by $28 \%$ ( $p<0.001$; Fig. $4 B$ ) and decreased plasma bilirubin concentrations by $37 \%(p<$
0.001; Fig. 4A), compared with controls. Figure $4 C$ shows that orlistat alone decreased plasma bilirubin concentrations by $10 \%$ (NS), and that cotreatment with PEG decreased plasma bilirubin by $24 \%$ ( $p<0.001$ ), compared with control animals. PEG thus did not enhance the rapid hypobilirubinemic effect of phototherapy but did increase that of orlistat treatment by $14 \%(p<0.05)$. Continuation of treatment in the PEG + phototherapy-treated animals for $2 \mathrm{wk}$, however, did result in a final decrease of $67 \%$, which was virtually identical to the decrease in the long-term experiment. Table 2 shows that there were no differences renal function, liver function, or growth rates between the various treatment groups.

\section{DISCUSSION}

In this study, we demonstrate that neither routine phototherapy nor experimental oral treatments (e.g. orlistat, UDCA, or $\mathrm{CaP}$ ) exert their hypobilirubinemic effect via acceleration of the gastrointestinal transit in Gunn rats. We also show that acceleration of the gastrointestinal transit by PEG enhances the therapeutic effects of both phototherapy and orlistat in these animals.

Several studies have suggested a relationship between gastrointestinal transit and plasma bilirubin levels. Conditions that delay the gastrointestinal transit, such as Hirschprungs disease (29) or fasting $(30,31)$, have been associated with an exaggeration of neonatal jaundice. Conditions that accelerate transit, such as prebiotic supplementation of infant formula, seem to mitigate jaundice in neonates $(32,33)$. We recently demonstrated that acceleration of the gastrointestinal transit by PEG effectively treated unconjugated hyperbilirubinemia in jaundiced Gunn rats (16). The strong relationship between the gastrointestinal transit and plasma UCB concentrations in that study prompted us to evaluate the mechanistic contribution of the transit time in phototherapy and in experimental oral treatments. The hypobilirubinemic effects of these treatments have traditionally been linked to different underlying mechanisms. Phototherapy, the routine treatment for neonatal jaundice, has been shown to exert its hypobilirubinemic effect by conversion of UCB into photoisomers (26). Experimental oral treatments, such as orlistat, UDCA, or $\mathrm{CaP}$, are thought to bind UCB within the gut lumen, thereby preventing its reabsorption and interrupting its enterohepatic circulation $(13,27,34)$. Interestingly, both phototherapy and oral treatments have also been suggested to accelerate the gastrointestinal transit. Phototherapy, especially intensive phototherapy, can induce diarrhea. Diarrhea is also a well-known potential side effect of orlistat and UDCA treatment $(35,36)$. Orlistat has been shown to accelerate gastric emptying (22), whereas UDCA treatment accelerated the gastrointestinal transit in dogs and can improve gastrointestinal motility defects in bile stone patients (20,37). Theoretically, phototherapy or oral treatments could thus well exert (part of) their hypobilirubinemic effect by acceleration of the gastrointestinal transit. Our Gunn rat model, however, allowed us to demonstrate that neither routine phototherapy nor experimental oral treatments exert their hypobilirubinemic effect via acceleration of the gastrointestinal transit. These findings prompted us to inves- 
Table 1. Renal and liver parameters after 6 wk of treatment

\begin{tabular}{|c|c|c|c|c|c|}
\hline & Controls & $\mathrm{PT}+\mathrm{PEG}$ & Orl + PEG & $\mathrm{UDCA}+\mathrm{PEG}$ & $\mathrm{Ca}+\mathrm{PEG}$ \\
\hline \multicolumn{6}{|l|}{ Renal parameters } \\
\hline Creat (mmol/L) & $17 \pm 9$ & $23 \pm 12$ & $31 \pm 11 *$ & $11 \pm 3$ & $11 \pm 4$ \\
\hline Urea (mmol/L) & $7.7 \pm 2.0$ & $6.0 \pm 1.3$ & $7.1 \pm 0.9$ & $6.1 \pm 1.2$ & $6.9 \pm 0.9$ \\
\hline \multicolumn{6}{|l|}{ Liver parameters } \\
\hline AST (U/L) & $96 \pm 37$ & $74 \pm 11$ & $86 \pm 17$ & $120 \pm 37$ & $98 \pm 29$ \\
\hline ALT U/L) & $35 \pm 25$ & $21 \pm 7$ & $21 \pm 10$ & $29 \pm 9$ & $28 \pm 6$ \\
\hline \multicolumn{6}{|l|}{ Growth parameters } \\
\hline Growth rate (\%, compared with $T=0$ wk) & $2.5 \pm 4.7$ & $-1.9 \pm 4.5$ & $-2.0 \pm 2.7$ & $-5.3 \pm 1.4 \dagger$ & $-1.3 \pm 2.2$ \\
\hline
\end{tabular}

For experimental setup, please refer to Figure 1. Plasma urea, creatinine, AST, ALT concentrations, and growth rate were determined after 6 wk of treatment. Data represent mean $\pm \mathrm{SD}$.

$* p<0.05$, compared with controls.

$\dagger p<0.01$, compared with controls.

PT, phototherapy; Orl, Orlistat.
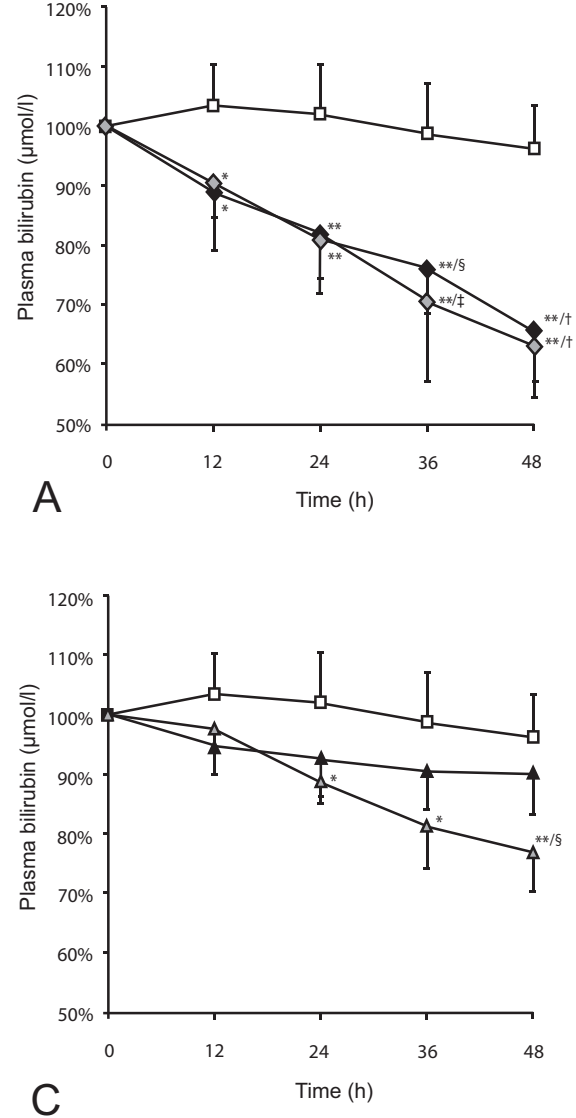
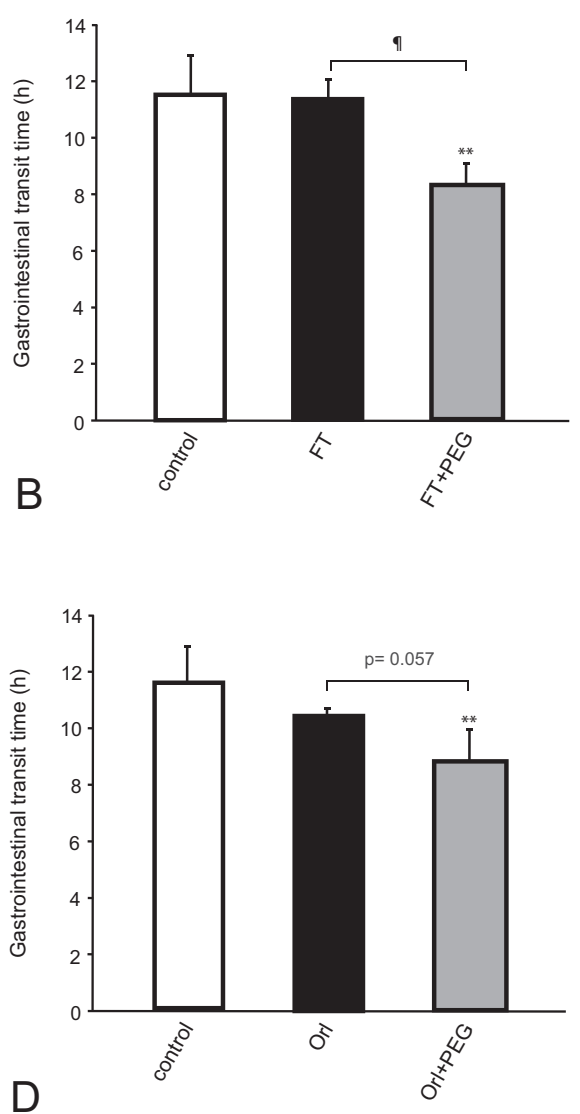

Figure 4. PEG cotreatment induces an additive hypobilirubinemic effect during orlistat (Orl) treatment $(A$ and $C$ ) and accelerates the gastrointestinal transit in all treatment groups $(B$ and $D)$. Gunn rats ( $n=6-7$ per group) received either no treatment or treatment with phototherapy, phototherapy $+P E G$, orlistat, or orlistat + $P E G$. The gastrointestinal transit was determined by administration of carmine red directly after the start of treatment as in Fig. $2 . * p<0.05 ; * * p<0.001$, compared with controls. $\llbracket p<0.001$, compared with single phototherapy treatment. $\$ p<0.05$; $\ddagger p<0.01 ; \dagger p<0.001$, compared with single orlistat treatment. $\square$ : Controls; phototherapy $(P T) ; \diamond$ : phototherapy + $P E G ; \mathbf{\Delta}$ : orlistat $(\mathrm{Orl}) ; \triangle$ : orlistat $+P E G$. tigate whether PEG cotreatment might induce an additional decrease in plasma bilirubin levels during these treatments. We added PEG cotreatment only after 3 wk to ensure steadystate conditions, which prevented any interference of nonsteady-state plasma bilirubin fluctuations (13,16-18).

PEG accelerated the gastrointestinal transit in all treatment groups and induced an additive therapeutic effect in phototherapy- and orlistat-treated animals. The most impressive effect was observed in the phototherapy + PEG treatment group, which concurred with the hypobilirubinemic result of adding phototherapy to PEG treatment alone in a previous study by us (16). The additive therapeutic effect ( $\sim 20 \%)$ thus occurred irrespective of whether phototherapy was added to PEG treatment (previous study) or vice versa (present study), indicating that both therapies truly complement each other (16). The efficacy of phototherapy + PEG treatment, which resulted in a final $67 \%$ decrease in plasma bilirubin levels, might well result from the distinct mechanisms by which phototherapy and PEG decrease plasma bilirubin levels. Phototherapy predominantly decreases plasma bilirubin levels by enhancing its disposal via the bile (26), whereas oral treatments, including PEG, selectively enhance net bilirubin diffusion from the blood into the intestinal lumen $(13,27)$. We and others have demonstrated in ${ }^{3} \mathrm{H}$-labeled bilirubin studies that a maximal therapeutic effect often results from combining therapies that enhance distinct pathways for bilirubin disposal $(13,26,27)$. The complementary effect of PEG and phototherapy might thus well result from the combination of their 
Table 2. Renal and liver parameters after 2 wk of treatment

\begin{tabular}{|c|c|c|c|c|c|}
\hline & Controls & PT & $\mathrm{PT}+\mathrm{PEG}$ & Orl & Orl + PEG \\
\hline \multicolumn{6}{|l|}{ Renal parameters } \\
\hline Creat (mmol/L) & $16 \pm 3$ & $13 \pm 2$ & $13 \pm 2$ & $19 \pm 4$ & $16 \pm 4$ \\
\hline Urea (mmol/L) & $8.6 \pm 1.8$ & $5.5 \pm 0.7 *$ & $6.9 \pm 1.5$ & $10 \pm 2$ & $5.8 \pm 0.9 \dagger$ \\
\hline \multicolumn{6}{|l|}{ Liver parameters } \\
\hline $\operatorname{AST}(\mathrm{U} / \mathrm{L})$ & $95 \pm 26$ & $95 \pm 17$ & $88 \pm 25$ & $125 \pm 45$ & $95 \pm 13$ \\
\hline $\operatorname{ALT}(\mathrm{U} / \mathrm{L})$ & $55 \pm 21$ & $38 \pm 7$ & $43 \pm 7$ & $73 \pm 12$ & $60 \pm 12$ \\
\hline \multicolumn{6}{|l|}{ Growth parameters } \\
\hline Growth rate (\%, compared with $T=0$ wk) & $0.4 \pm 2.4$ & $-0.1 \pm 0.0$ & $3.7 \pm 2.0$ & $4.4 \pm 1.4$ & $0.3 \pm 2.5$ \\
\hline
\end{tabular}

For experimental setup, please refer to Figure 3. Plasma urea, creatinine, AST, and ALT concentrations, and growth rate were determined after 2 wk of treatment. Data represent mean $\pm \mathrm{SD}$.

$* p<0.01$, compared with controls.

$\dagger p<0.05$, compared with controls.

PT, phototherapy; Orl, Orlistat.

distinct hypobilirubinemic mechanisms. The additive effect of PEG was not observed during the first days of phototherapy treatment. We speculate that this occurred because short-term phototherapy extracted bilirubin at a maximal rate from the body. This rate could thus not be further increased by PEG cotreatment. Short-term orlistat treatment, however, was notably less effective compared with phototherapy. In agreement with our postulate above, PEG was a useful adjunct strategy in this treatment group.

PEG cotreatment did not induce an additive therapeutic effect in UDCA- or CaP-treated animals. This lack of additive effect cannot be attributed to an insufficient acceleration of the gastrointestinal transit, which was comparable between all PEG-treated groups. PEG administration, however, has several effects on the intestinal milieu that might counter the UDCA or CaP-induced decrease in plasma UCB levels. First, PEG decreases the amount of bile salts in the feces (13). This, evidently, would counteract the effect of simultaneous UDCA feeding. Second, PEG decreases the formation of secondary bile salts, possibly by affecting the microflora that promotes bile salt metabolism. This microflora, however, is also involved in the irreversible degradation of intestinal bilirubin into urobilinoids, which is promoted by UDCA feeding $(13,16)$. PEG might thus well interfere with the apparent ability of UDCA to promote intestinal bilirubin degradation. Finally, PEG increases the amount of intestinal water and accelerates the gastrointestinal transit. This might well prevent the precipitation of amorphous $\mathrm{CaP}$ with intestinal bilirubin during CaP treatment (34).

Animals that were treated with UDCA + PEG showed a small $(-5 \%)$, but significant, decrease in growth rate compared with control animals. Although this was not observed in other groups, it should be emphasized that diarrhea and malabsorption of vitamins (A, D, E, K) have been reported during orlistat, UDCA, and CaP treatment $(18,35,36,38)$. Regular assessments of the nutritional (vitamin) status and/or vitamin supplementation would be indicated if one would combine these treatments with a laxative such as PEG in patient studies. These precautions may not apply for the combination of PEG with phototherapy, which seems safe and deserves further exploration in hyperbilirubinemic patient studies.

In conclusion, our data show that that neither phototherapy nor orlistat, UDCA, or CaP exerts its hypobilirubinemic effect via acceleration of the gastrointestinal transit. Combining PEG-induced acceleration of the gastrointestinal transit with phototherapy decreased plasma bilirubin levels by $67 \%$ in Gunn rats. Our results support the evaluation of PEG cotreatment during phototherapy in clinical trials, e.g. in CriglerNajjar patients.

\section{REFERENCES}

1. Crigler JF Jr, Najjar VA 1952 Congenital familial nonhemolytic jaundice with kernicterus. Pediatrics 10:169-180

2. Arias IM, Gartner LM, Cohen M, Ezzer JB, Levi AJ 1969 Chronic nonhemolytic unconjugated hyperbilirubinemia with glucuronyl transferase deficiency. Clinical, biochemical, pharmacologic and genetic evidence for heterogeneity. Am J Med 47:395-409

3. Shapiro SM 2005 Definition of the clinical spectrum of kernicterus and bilirubininduced neurologic dysfunction (BIND). J Perinatol 25:54-59

4. Ahlfors CE, Amin SB, Parker AE 2009 Unbound bilirubin predicts abnormal automated auditory brainstem response in a diverse newborn population. J Perinatol 29:305-309

5. Ahlfors CE, Wennberg RP, Ostrow JD, Tiribelli C 2009 Unbound (free) bilirubin: improving the paradigm for evaluating neonatal jaundice. Clin Chem 55:1288-1299

6. Ostrow JD, Mukerjee P, Tiribelli C 1994 Structure and binding of unconjugated bilirubin: relevance for physiological and pathophysiological function. J Lipid Res $35: 1715-1737$

7. Ostrow JD, Pascolo L, Brites D, Tiribelli C 2004 Molecular basis of bilirubininduced neurotoxicity. Trends Mol Med 10:65-70

8. Zucker SD, Goessling W, Hoppin AG 1999 Unconjugated bilirubin exhibits spontaneous diffusion through model lipid bilayers and native hepatocyte membranes. J Biol Chem 274:10852-10862

9. Ostrow JD, Pascolo L, Shapiro SM, Tiribelli C 2003 New concepts in bilirubin encephalopathy. Eur J Clin Invest 33:988-997

10. van der Veere CN, Sinaasappel M, McDonagh AF, Rosenthal P, Labrune P, Odievre M, Fevery J, Otte JB, McClean P, Burk G, Masakowski V, Sperl W, Mowat AP, Vergani GM, Heller K, Wilson JP, Shepherd R, Jansen PL 1996 Current therapy for Crigler-Najjar syndrome type 1: report of a world registry. Hepatology 24:311-315

11. Yohannan MD, Terry HJ, Littlewood JM 1983 Long term phototherapy in CriglerNajjar syndrome. Arch Dis Child 58:460-462

12. Lester R, Schmid R 1963 Intestinal absorption of bile pigments. I. The enterohepatic circulation of bilirubin in the rat. J Clin Invest 42:736-746

13. Cuperus FJ, Hafkamp AM, Havinga R, Vitek L, Zelenka J, Tiribelli C, Ostrow JD, Verkade HJ 2009 Effective treatment of unconjugated hyperbilirubinemia with oral bile salts in Gunn rats. Gastroenterology 136:673-682

14. Kotal P, Van der Veere CN, Sinaasappel M, Elferink RO, Vitek L, Brodanova M, Jansen PL, Fevery J 1997 Intestinal excretion of unconjugated bilirubin in man and rats with inherited unconjugated hyperbilirubinemia. Pediatr Res 42:195-200

15. Lester R, Schmid R 1963 Intestinal absorption of bile pigments. II. Bilirubin absorption in man. N Engl J Med 269:178-182

16. Cuperus FJ, Iemhoff AA, van der Wulp M, Havinga R, Verkade HJ 2010 Acceleration of the gastrointestinal transit by polyethylene glycol effectively treats unconjugated hyperbilirubinaemia in Gunn rats. Gut 59:373-380

17. Hafkamp AM, Havinga R, Sinaasappel M, Verkade HJ 2005 Effective oral treatment of unconjugated hyperbilirubinemia in Gunn rats. Hepatology 41:526-534

18. Hafkamp AM, Nelisse-Haak R, Sinaasappel M, Oude Elferink RP, Verkade HJ 2007 Orlistat treatment of unconjugated hyperbilirubinemia in Crigler-Najjar disease: a randomized controlled trial. Pediatr Res 62:725-730

19. Van der Veere CN, Jansen PL, Sinaasappel M, Van der Meer R, Van der Sijs H, Rammeloo JA, Goyens P, Van Nieuwkerk CM, Oude Elferink RP 1997 Oral calcium phosphate: a new therapy for Crigler-Najjar disease? Gastroenterology 112:455-462 
20. Colecchia A, Mazzella G, Sandri L, Azzaroli F, Magliuolo M, Simoni P, BacchiReggiani ML, Roda E, Festi D 2006 Ursodeoxycholic acid improves gastrointestinal motility defects in gallstone patients. World J Gastroenterol 12:5336-5343

21. Borovicka J, Schwizer W, Guttmann G, Hartmann D, Kosinski M, Wastiel C, Bischof-Delaloye A, Fried M 2000 Role of lipase in the regulation of postprandial gastric acid secretion and emptying of fat in humans: a study with orlistat, a highly specific lipase inhibitor. Gut 46:774-781

22. Schwizer W, Asal K, Kreiss C, Mettraux C, Borovicka J, Rémy B, Güzelhan C, Hartmann D, Fried M 1997 Role of lipase in the regulation of upper gastrointestinal function in humans. Am J Physiol 273:G612-G620

23. Ebbesen F, Edelsten D, Hertel J 1980 Gut transit time and lactose malabsorption during phototherapy. I. A study using lactose-free human mature milk. Acta Paediatr Scand 69:65-68

24. Ebbesen F, Edelsten D, Hertel J 1980 Gut transit time and lactose malabsorption during phototherapy. II. A study using raw milk from the mothers of the infants. Acta Paediatr Scand 69:69-71

25. De Curtis M, Saitta F, Matteoli M, Paludetto R, Ciccimarra F, Guandalini S 198 Evidence for secretory type diarrhoea in infants treated by phototherapy. Lancet 319:909

26. Ostrow JD 1971 Photocatabolism of labeled bilirubin in the congenitally jaundiced (Gunn) rat. J Clin Invest 50:707-718

27. Hafkamp AM, Havinga R, Ostrow JD, Tiribelli C, Pascolo L, Sinaasappel M, Verkade HJ 2006 Novel kinetic insights into treatment of unconjugated hyperbilirubinemia: phototherapy and orlistat treatment in Gunn rats. Pediatr Res 59:506-512

28. Call NB, Tisher CC 1975 The urinary concentrating defect in the Gunn strain of rat. Role of bilirubin. J Clin Invest 55:319-329
29. Gartner LM 2001 Breastfeeding and jaundice. J Perinatol 21:S25-S29; discussion S35-S39

30. Kotal P, Vitek L, Fevery J 1996 Fasting-related hyperbilirubinemia in rats: the effect of decreased intestinal motility. Gastroenterology 111:217-223

31. Bertini G, Dani C, Tronchin M, Rubaltelli FF 2001 Is breastfeeding really favoring early neonatal jaundice? Pediatrics 107:E41

32. Mihatsch WA, Hoegel J, Pohlandt F 2006 Prebiotic oligosaccharides reduce stool viscosity and accelerate gastrointestinal transport in preterm infants. Acta Paediatr 95:843-848

33. Bisceglia M, Indrio F, Riezzo G, Poerio V, Corapi U, Raimondi F 2009 The effect of prebiotics in the management of neonatal hyperbilirubinaemia. Acta Paediatr 98:1579-1581

34. van der Veere CN, Schoemaker B, van der Meer R, Groen AK, Jansen PL, Oude Elferink RP 1995 Rapid association of unconjugated bilirubin with amorphous calcium phosphate. J Lipid Res 36:1697-1707

35. Filippatos TD, Derdemezis CS, Gazi IF, Nakou ES, Mikhailidis DP, Elisaf MS 2008 Orlistat-associated adverse effects and drug interactions: a critical review. Drug Saf 31:53-65

36. Hempfling W, Dilger K, Beuers U 2003 Systematic review: ursodeoxycholic acidadverse effects and drug interactions. Aliment Pharmacol Ther 18:963-972

37. Kruis W, Haddad A, Phillips SF 1986 Chenodeoxycholic and ursodeoxycholic acids alter motility and fluid transit in the canine ileum. Digestion 34:185-195

38. Haynes RC 1988 Agents affecting calcification: calcium, parathyroid hormone, calcitonin, vitamin D, and other compounds. In: Goodman Gilman A, Rall TW, Nies AS, Taylor P (eds) The Pharmacological Basis of Therapeutics. Pergamon, New York, NY, pp 1496-1504 